\title{
Audio Lingual Model
}

\section{Tazeen Jamal Siddiqui \\ Hyderabad}

\begin{abstract}
The paper intends to discuss a model to improve the quality of spoken English of the students using various drills performed between the teacher and student.
\end{abstract}

Keywords: Audio Lingual Model; Drills;Low cost; Speaking

\section{Introduction}

Teaching is the process of carrying out the activities in getting students to learn. While teaching , speaking is the process of making students to produce or practice the target and express it orally ,Actually, the material from the teacher to the students must be appropriated with the syllabus of the certain school, in order that the students are able to absorb it and they will be able to communicate by using the target language(English) orally. The ALM shall be helpful to our young teachers because it is user friendly. Our model will also help in English medium school in rural areas where the teachers are ill equipped and cannot use digital aides for teaching the students.

\section{Background Of ALM}

The ALM of teaching English as a second language had its origins during World War II when it became known as the Army method. It was developed as a reaction to the grammar-translation method of teaching foreign languages. Grammar-translation had been used to teach for thousands of years, but the method was perceived as taking too long for learners to be able to speak in the target language. The ALM set out to achieve quick communicative competence through innovative methods. From about 1947-1967 the AudioLingual approach was the dominant foreign language teaching method in the United States.

\section{Audio Lingual Model (ALM)}

ALM is a style of teaching used in teaching foreign languages. It is based on behaviorist theory which professes that certain traits of living beings, and in this case humans, could be trained through a system of reinforcement. Skills are taught in the following order : listening, speaking, reading, and writing.

\section{Techniques Used In ALM}

The audio lingual model is an approach that emphasizes the vocabulary and trains the grammatical sentence pattern based on the context and without any error.

- Repeatition

- Substitution

- $\quad$ Backword and buildup

- Chain

- Expansion

- Clause combination
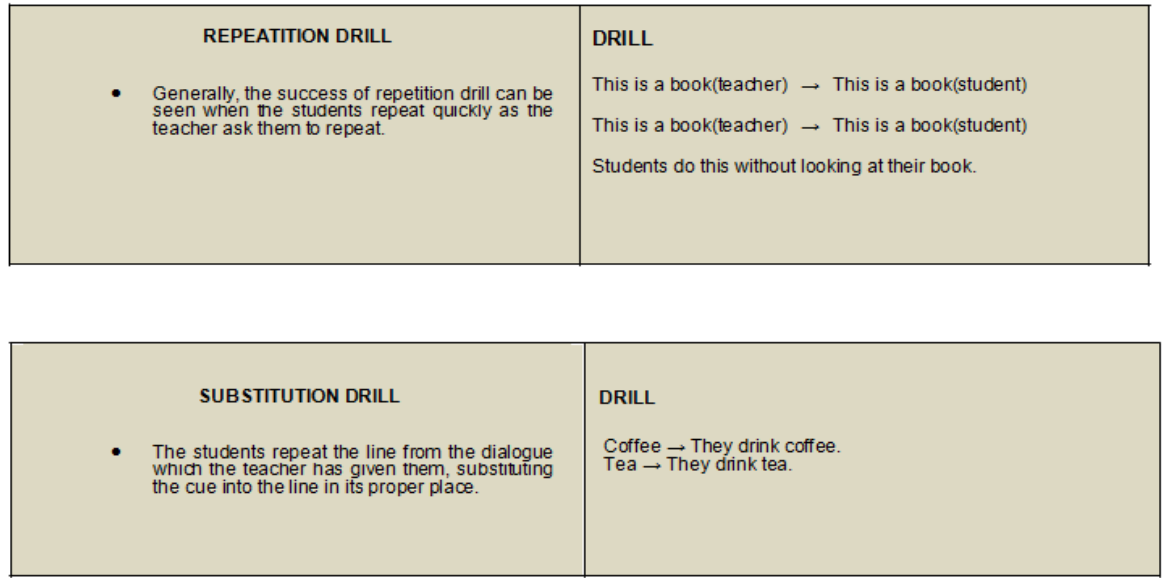


\begin{tabular}{|c|c|}
\hline $\begin{array}{l}\text { BACKWORD AND BUILDUP DRILL } \\
\text { - The teacher breaks down the line into several } \\
\text { parts. The students repeat a part of the sentence, } \\
\text { usually the last phrase of the line. Then, following } \\
\text { the teacher's cue, the students expand what they } \\
\text { are repeating part by part until they are able to } \\
\text { repeat the entire line. }\end{array}$ & $\begin{array}{l}\text { DRILL T-TEACHER; S-STUDENT } \\
\text { T: the flowers } \\
\mathrm{S} \text { : the flowers } \\
\mathrm{T} \text { : watering the flowers } \\
\mathrm{S} \text { : watering the flowers } \\
\mathrm{T} \text { : is watering the flowers } \\
\mathrm{S} \text { : is watering the flowers } \\
\mathrm{T} \text { : Ian is watering the flowers. } \\
\mathrm{S} \text { : Ian is watering the flowers. }\end{array}$ \\
\hline
\end{tabular}

\begin{tabular}{|c|c|}
\hline $\begin{array}{l}\text { CHAIN DRILL } \\
\text { - The teacher begins the chain by greeting a } \\
\text { particular student, or asking him a question. } \\
\text { That student responds, and then tums to the } \\
\text { student sitting next to him. }\end{array}$ & $\begin{array}{l}\text { DRILL } \\
\text { T: Hello, what's your name? } \\
\text { S1: My name is John Smith. (He tums to the student next to } \\
\text { her.) Hello, what's your name? } \\
\text { S2: My name is Mary Clinton. (She turns to the student next to } \\
\text { her.) Hello, what's your name? } \\
\text { S3: My name is Peter. }\end{array}$ \\
\hline
\end{tabular}
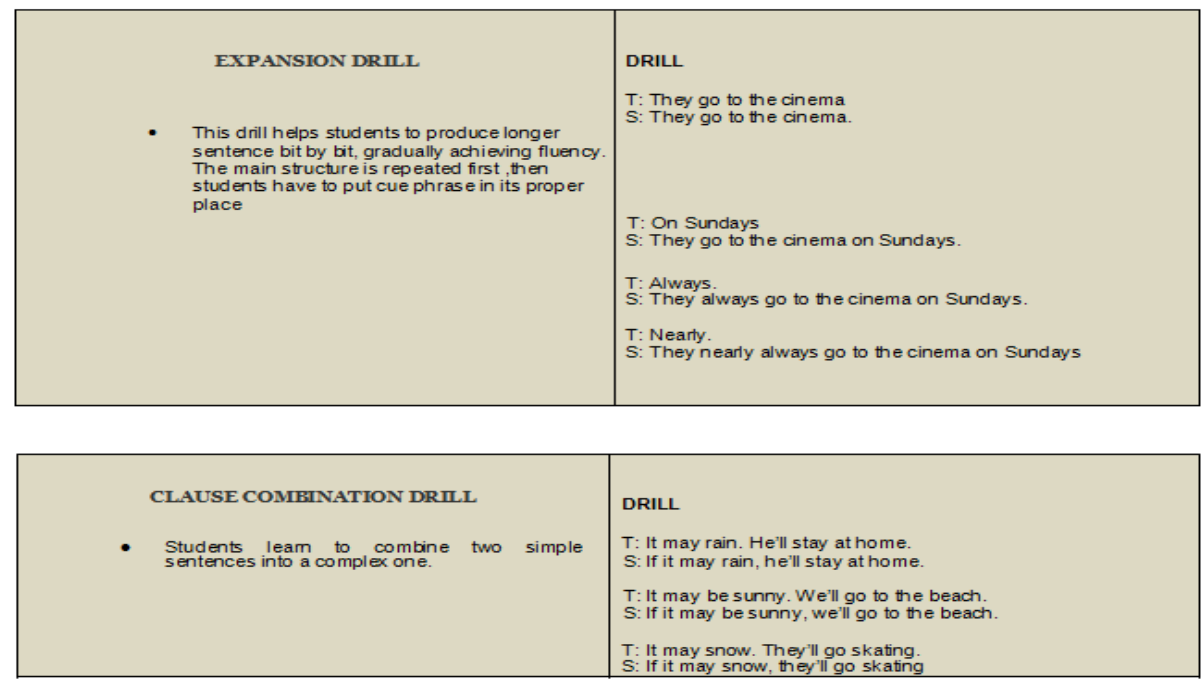

Data Showing Implementation of ALM Drills

Date :9-12-2015
Responses of the 2 ALM Drills :
1-Repeatition
2-Substitution
\begin{tabular}{|l|c|c|c|}
\hline CLASS & Total No of Students & ALM Resonse Students & Remaining Kids \\
\hline PP1-A & 19 & 15 & 4 \\
\hline PP1-B & 16 & 13 & 3 \\
\hline PP1-C & 20 & 16 & 4 \\
\hline PP1-D & 20 & 17 & 3 \\
\hline PP1-E & 11 & 7 & 4 \\
\hline
\end{tabular}



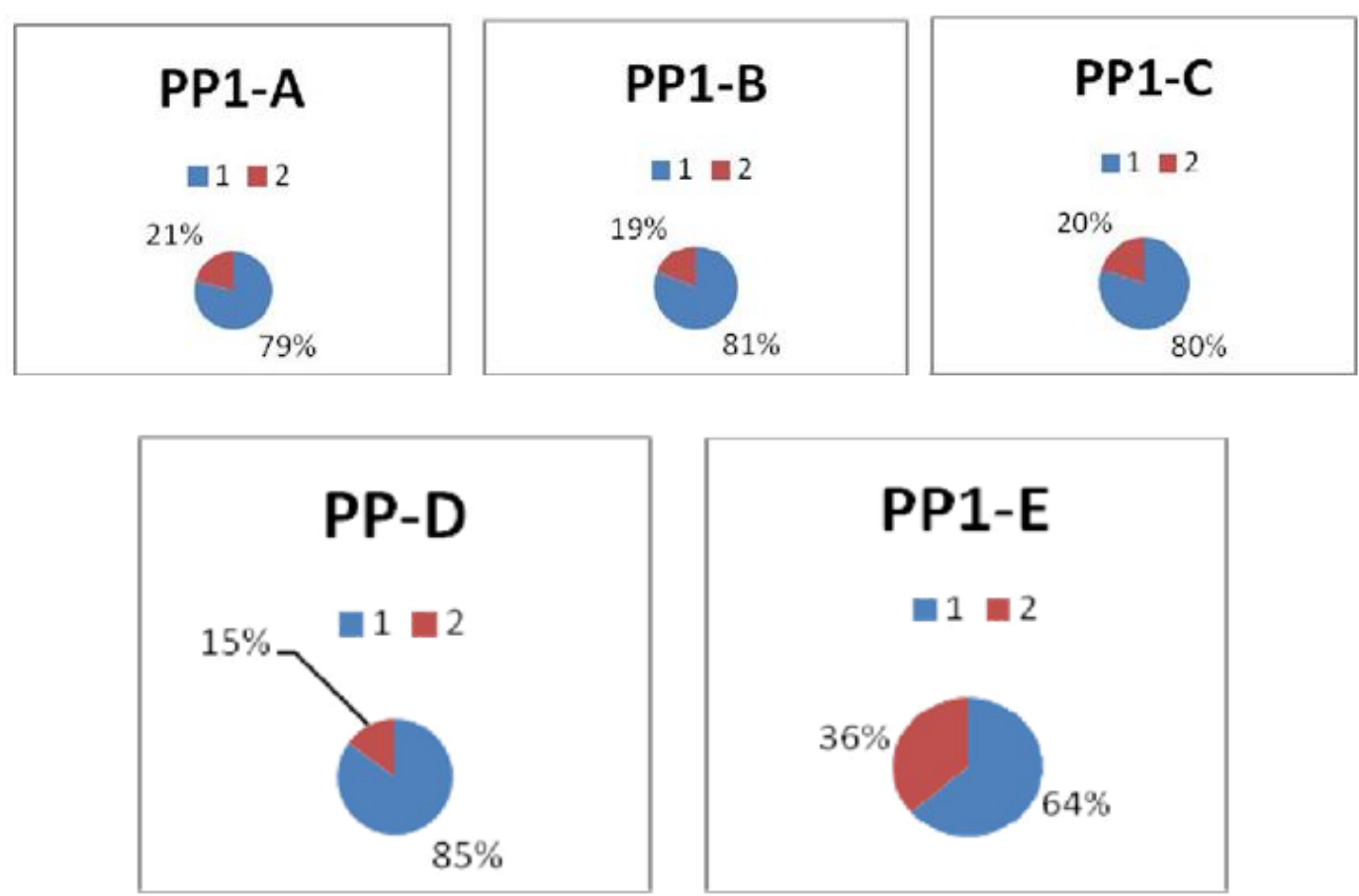

Fig:1

\section{Conclusion}

Using ALM improves the communication skills of students as well as enhances teaching skills of teachers. It complements any curriculum and can be implemented with a very low cost. 